\title{
THE MORE RECENT DEVELOPMENTS IN THE STUDY OF ANAPHYLACTIC PHENOMENA *
}

\author{
HANS ZINSSER \\ NEW YORK
}

I

It is a fundamental biological truth that the systematic treatment of an animal with a foreign protein, if this is administered by any route other than that of the alimentary canal, induces profound physiological changes. These changes are primarily recognizable by the appearance in the circulating blood of substances which superficially react with the injected protein. For convenience of discussion we speak of these reaction products as antibodies, and of the injected substances, which possess this power of inducing their formation, as antigens.

Antigens, then, are all substances which injected into the animal body, induce specific antibody formation. They form a large group in nature and are chemically proteins; indeed, we may say that all known proteins may act as antigens. Whether or not this term may also include lipoid-protein combinations, lipoids or the higher protein derivatives is as yet uncertain and need not in the present connection concern us.

We may divide antigenic substances into two main classes. One of these comprises all of those substances of bacterial, animal or vegetable origin which, injected into the animal body, give rise to specific neutralizing or antitoxic properties in the blood of the injected animal. These are the bacterial exotoxins, the snake venoms, some powerful vegetable poisons and proteolytic and other enzymes of animals and plants. They are all substances which are powerfully active--some of them strongly toxic to the living animal, others true enzymes or ferments. Indeed all of them possess properties which at least suggest our placing them into the class of enzymes in general. The number of such substances known is limited. The reaction they call forth in the animal body seems aimed directly at the specific neutralization of their respective activities, and is so unique and different from that induced by other antigens that it would be convenient had we another term like "antitoxinogen" to set them apart by themselves.

* Submitted for publication Feb. 16, 1915.

* Lecture delivered before the Harvey Society of New York, Jan. 30, 1914. 
The other class of antigens comprises all proteins which are inactive, showing in themselves neither toxic nor enzyme-like properties. Introduced into the animal body parenterally, they call forth a response of a nature entirely unlike that of the antitoxins, and which as far as we can fathom its purpose seems aimed merely at the assimilation or the removal of the infected substance. For the cells of the animal cannot utilize the foreign protein as such, and thus it is only foreign proteins injected into an animal that act antigenically and no antibodies are formed when homologous material is injected.

This large group composed of all formed and unformed substances in nature in which a protein structure is involved, does not induce the formation of anything like the neutralizing antitoxins spoken of above. The antibodies appearing in animals treated with such substances have been spoken of as cytolysins or cytotoxins-precipitins-and in the case of formed antigens like bacteria or blood cells-agglutinins and opsonins. It is our opinion that all these various antibodies are identical in structure and significance. The probable identity of agglutinins and precipitins was suggested long ago by Paltauf, and the identity of precipitins with the antibodies which sensitize foreign proteins to the action of alexin or complement has been rendered more probable, we believe, by our own experiments. The terms agglutinin-lysin-precipitin and opsonin are all descriptive of effects produced when an antigen meets its specific antibody. These effects will differ according to the physical condition of the antigen. We believe that it is most likely, both from a study of the work of others and our own experiments aimed at this point directly, that the visible agglutination or precipitation are secondary effects incidental to the colloidal nature of the reacting bodies and to the quantitative proportions in which the reactions occur, the essential process being the union of antigen and antibody, by which the former is rendered amenable to the action of complement (alexin) or leukocyte as the case may be. It is not necessary, at any rate, to assume that functionally there is more than one variety of antibody, this one being the specific sensitizer. However this may be, the definite fact remains that injection of antigens of this second class into animals induces specific reaction bodies or antibodies in the plasma of the treated animal which can be shown to unite with the homologous antigen in vitro, and which probably do so in the body of the animal when the antigen is reinjected into a subject in which antibody formation has taken place.

We must not forget, however, that the observation of antibodies in the circulating blood is but one of the changes that have taken place in the treated animal. Much has been made of this phase of the problem because serum antibodies are readily studied in vitro; but 
their origin of course must be sought in the body cell, in which the original and most profound changes must necessarily have taken place during such treatment, changes the nature of which are to a large extent still a mystery, but on which ultimately depend the important physiological difference between treated and untreated animals. For such changes-whether we refer to those immediately under discussion, namely, those of allergy or anaphylaxis, or whether we think of the so-called immunity remaining after attacks of many diseasesremain present long after the circulating antibodies have disappeared and must therefore be regarded as associated with profound alterations in the ultimate tissue unit, the body cell.

Pasteur's observation that animals systematically treated with sublethal doses of bacteria became specifically more resistant to subsequent infection, carries in it all the principles of the process of which we speak as "active immunization," and all the modifications and adaptations to special cases which we now employ are based on this simple truth. The successful transference of such increased powers of resistance to normal animals with the serum of the immunized individual, by Behring and his collaborators, gave us "passive immunization," and these two discoveries are the pillars on which all our complicated subsequent development of details has rested. Since with bacteria and their poisons the process implied the protection of the body against disease or death, we have, rather unfortunately, come to speak of these procedures as "immunization," although the reactions of the animal body to injections of bacteria, reactions on which incidentally the protection depends, are in principle identical with similar reactions resulting from the injection of entirely innocuous substances, such as egg albumin, blood serum or blood corpuscles. It is, therefore, misleading when we speak of the immunization of an animal to, for instance, sheep cells or horse serum. A physiological exchange takes place in such animals entirely analogous with that which occurs in those receiving bacterial protein, but the substances injected are in the former entirely harmless; and indeed, as we shall see, the animal, while entirely immune to large quantities at the first injection, may be severely injured or even killed by subsequent administrations of the same substance. Thus the animal most "immune" to horse serum is the one that has never received an injection of horse serum. It is necessary, therefore, to emancipate ourselves from the misleading elements in the habitual terminology so that we may avoid confusion in grasping underlying principles.

The essential feature common to all antigen injections, therefore, is that of specific antibody formation. That their production in the case of living or dead bacteria-harmful in themselves-protects the 
animal from invasion and prevents development and multiplication of the organisms once admitted, though of the greatest practical importance, is purely incidental.

It is not impossible that the physiological reaction indicated among other things by the circulating antibodies denotes a mechanism aimed at the more effective assimilation and elimination of the body-foreign antigens that have been injected, and this, in the case of the bacterial cell, which of course represents a foreign protein, has the effect of protection against invasion. This point of view of the significance of antibodies is the so-called theory of "parenteral digestion" of which we will have more to say directly. We must remember at any rate that in all cases in which, clinically or experimentally, we are confronted with the presence of foreign antigens in the blood and tissues, we are dealing with abnormal conditions in which the mechanism available under normal circumstances for the disposal of foreign proteins which may gain entrance accidentally in extremely minute quantities is under a strain and abnormally active. The extreme quantitative increase of the antibodies is alone sufficient testimony for this, and under the special conditions which we are about to discuss, the repeated introduction of such antigens into the body of an animal in which specific reaction bodies have been induced, whether these are freely circulating or still parts of the cells which produced them, may have illness or even death as a consequence. This is anaphylaxis.

To approach this subject logically without allowing secondary factors to divert our attention from the fundamental principles involved, we should not limit this term to any arbitrarily stated train of symptoms, nor should we attempt too rigidly to limit the definition of what we call anaphylaxis. Indeed, from the point of view of human pathology, it is of quite as much, if not of more, importance to study the effects of slow and slight injuries of this category, than it is to observe them only in the extreme and stormy manifestations of acute anaphylactic death. The former are the types of reactions occurring in the ordinary incidents of life. The latter are extreme results of experimental procedures and are for this reason of course more likely to reveal the underlying principles. But it would lead to false logic in our deductions were we to mistake a difference in degree for a difference in principle.

In the light of our present understanding, therefore, we should broadly define the term as the injury, acute or slow, severe or slight, which under manifold circumstances, may follow on the meeting of an antigen with its specific antibody within the animal body. When such injury fails to result in the case of the spontaneous entrance or the experimental injection of bacteria into an immunized subject it is 
probably because the organisms are disposed of before the amount of foreign protein is sufficient to permit such a harmful reaction. What these circumstances are is the problem before us. In the case of innocuous foreign proteins such as blood serum or cells incapable of multiplication, it is doubtful whether immunity-that is, ability to escape harm on reinjection-ever exists. However, we do know that the animal may be nonsensitive, as on first injection when practically no specific antibodies are present, or it may be hypersusceptible, anaphylactic, or (the most comprehensive term) allergic.

II

We may discuss briefly the conditions under which so-called anaphylactic shock may be experimentally elicited in animals. Although of relatively recent development, in their details, the observations which underlie the phenomena took root in the early history of serum investigation. Morgenroth ${ }^{1}$ speaks of an observation by Magendie as early as in 1839 in which he describes the sudden death of dogs when repeatedly injected with egg albumin. Flexner reported similar deaths in rabies repeatedly injected with dog serum. Richet and Héricourt ${ }^{2}$ in 1898 showed that toxic eel serum injected into dogs would kill at the second injection in far smaller doses than were necessary to kill at the first injection. Similar significance attaches to the work done by Portier and Richet on actinocongestine. Properly belonging in this group of phenomena are the early observations on hypersensitiveness to toxins in repeatedly injected animals made by Behring and his collaborators. The problem was brought into particular prominence by the observations of Arthus $^{3}$ in 1903, who found that horse serum injected into rabbits at intervals of several days would eventually, in the later injections, give rise to severe infiltration and edema, and almost at the same time Theobald Smith noticed the great susceptibility to horse serum acquired by guinea-pigs that had been used for diphtheria antitoxin standardization. Independently and with great clearness of vision von Pirquet ${ }^{4}$ had made similar investigations on clinical material, and in his work on serum sickness appears to have grasped the fundamental significance of the phenomena with a thoroughness not shared by most of his contemporaries. The historical development of this subject and the experimental conditions under which hypersusceptibility may appear were the subject of a paper read before this society some years ago by two of the pioneer workers in this subject,

1. Morgenroth: Ehrlich Gesammelte Arbeiten, translation, Wiley \& Son, New York, 1906, footnote, p. 332.

2. Richet and Héricourt: Compt. rend. Soc. de biol., 1898, xv, 137.

3. Arthus: Compt. rend. Soc. de biol., 1v, 817.

4. Von Pirquet and Schick: Die Serumkrankheit, Wien, Deuticke, 1906. 
Rosenau and Anderson. ${ }^{5}$ The fundamental facts concerning the anaphylactic reaction were worked out almost immediately under the observations of Theobald Smith and Arthus by these workers and by Otto $^{6}$ in Germany. I may be permitted to summarize this early work and the fundamental principles of anaphylaxis very briefly in order that we may not spend our time in detailed consideration of facts entirely familiar to most of us.

It is now certain that hypersusceptibility may be produced in human beings, in guinea-pigs, in rabbits, in dogs, in sheep and probably in all mammals, if we were to investigate them carefully.

The condition may be produced by treatment with any of the substances known to us which have the property of antibody froduction; in other words, with all substances in nature of which we speak as antigens.

The condition is like other antigen-antibody reactions, specific within the limits of specificity recognized for all such reactions. It is certain that in socalled active sensitization, hypersusceptibility develops only after lapse of a definite interval, and this interval depends to a certain extent on the amount administered at the first injection.

An animal once sensitized if not reinjected may remain sensitive for a long period; its sensitiveness will disappear immediately after recovery from a nonfatal reinjection or the animal may temporarily be desensitized by reinjection of the antigen at a period before hypersusceptibility has developed.

Of the greatest theoretical importance furthermore is the fact that a normal animal may be rendered sensitive, passively, by the injection of blood serum from an actively sensitized animal, or by the blood serum of any animal which has been once or repeatedly injected with the antigen; and according to Doerr and Russ and others there is a definite parallelism between the capacity of a serum passively to sensitize an animal, and its contents in specific antibodies.

There are many other facts which are of importance, but which for the present we will neglect, since these are the fundamental phenomena on which we may build our discussion. We may also dismiss very briefly such earlier theories of anaphylaxis as those of Gay and South$\operatorname{ard}^{7}$ and Besredka, ${ }^{8}$ in which attempts were made to show that the substance which sensitizes is not identical with that which is responsible for the development of shock in the reinjected animal. We may, indeed, disregard as premature theories, all those in which the anaphylactic reaction is removed from the sphere of true antigen-antibody reaction. Indeed, von Pirquet and Rosenau and Anderson from the beginning regarded anaphylaxis as the result of the reaction between the reinjected antigen and the antibody formed in response to the first administration; and indeed, this is the essential premise of the still

5. Rosenau and Anderson: Bull. 29, U. S. P. H. S., 1906; Bull. 30, 1906; Bull. 36, 1907 ; Jour. Med. Research, 1906, xv; ibid., 1907, xvi; Jour. Infect. Dis., 1907, iv; ibid., 1908, v.

6. Otto: Das Theobald Smithsche Phaenomen, etc., von Leuthold Gedenkschrift, 1905, i.

7. Gay and Southard: Jour. Med. Research, 1907, xvi.

8. Besredka: Bull. de l'Inst. Pasteur, 1908, vi, 826. 
earlier view of Vaughan. We may accept it at present, identifying the anaphylactic antigen with antigens in general, and the anaphylactic antibody with the protein antibody, not distinguishing for this purpose between agglutinins, precipitins, or cytolysins.

The symptoms which follow on the reinjection of antigen into sensitive animals may show a wide range of variation according to the degree of sensitiveness and amounts injected. In acute anaphylaxis of guinea-pigs, which as you know has been the most thoroughly studied, there is a rapid and severe death which may not occupy more than a fraction of a minute or at most five to ten minutes. The animals repeatedly show restlessness, cough, pass urine and feces, develop severe dyspnea, with infrequent respiration in which there seems to be almost complete immobilization of the chest wall and in which finally only shallow, irregular, spasmodic efforts take place. This, as Auer and Lewis have shown, is due to tetanic contraction of the small bronchioles, with occlusion of the air passages, practically no air entering the lungs. As the dyspnea develops, there may be at the same time spasmodic twitching of the limbs, retraction of the head and general convulsions.

When for some reason or other the reaction is not so severe the animal may show merely general signs of illness, ruffling of the fur, twitching and restlessness, with respiratory difficulty of varying degree, coughing, and evacuation of urine and feces. In rabbits the symptoms are often less rapid in development, but in general principles are similar; in rabbits there is more frequently in the moderate cases a gradual muscular weakness in which the animal lies flat on the ground unable to support itself on its legs, a condition which may proceed for long periods. Death is largely respiratory and the heart may continue to beat for a long time after respiration has completely stopped.

There is a sinking of blood pressure and a depression of temperature.

The coagulation time of the blood is lengthened, there is apparently a depression of the leukocytes, and according to a number of investigators, who have been recently confirmed by Behring, there is a disappearance of blood platelets and an increased flow of lymph.

Pathologically in an animal dead of anaphylaxis there may be petechial hemorrhages, according to Gay and Southard, in the heart muscle, pleura and intestinal wall and there may be fatty degeneration of the vascular endothelium. In guinea-pigs especially there is a marked emphysematous dilatation of the lungs which is very constant, although according to Doerr it is not absolutely characteristic of this condition. Apart from the anatomical changes following acute anaphylaxis, frequently repeated injections of small doses of horse serum or egg white in dogs, cats, rabbits and guinea-pigs have been shown by Longcope to produce cell injury in various organs, especially in the liver, myocardium and kidneys.

The sudden onset, the nature of the reaction in the animal and the pathological lesions seem to indicate that the injury as occurring in anaphylaxis is due to a poison. It appears, then, that an animal is sensitive to a protein at certain stages at which specific antibodies to the sensitizing protein have been formed, and that under special circumstances the meeting of antigen with antibody within the animal, results in a reaction in consequence of which the poisonous substance is liberated. This being the logical point of view on the basis of avail- 
able knowledge, it was quite natural that many investigators were attracted by the theory of parenteral digestion. ${ }^{9}$

III

It is one of the earliest premises of Pfeiffer's conception of bacteriolysis that the cell-dissolving action of immune serum liberates a preformed poisonous substance or endotoxin from the bacterial cell. It may be remembered that early in the history of such researches Pfeiffer and some of his pupils showed that an immune animal could be killed more quickly by large doses of dead bacteria than could a normal animal, an experiment from which the conclusion was drawn that the more rapid bacteriolysis in the immunized animal resulted in a more rapid liberation of the endocellular poisons. This point of view has been many times brought forward, and of recent years most clearly by Wolf-Eisner.

It is also a point of view represented by the theory of Nicolle, who similarly tried to explain anaphylaxis by the liberation of poisonous substances from the antigen through the action of the cytolysins or "albuminolysins."

As the investigation of antibody formation against foreign proteins of inherently harmless nature progressed, the belief gained strength that antibodies in facilitating the chemical disintegration of the injected foreign protein represented a sort of emergency apparatus, for parenteral digestion and consequent assimilation. Throughout the development of Metchnikoff's ideas of immunity it is plain that he had tended toward such an interpretation, looking on the process of phagocytosis as a method of facilitating the removal of undissolved foreign substances from the tissues and blood, while the serum antibodies were conceived as more particularly concerned with the unformed foreign

9. The curious changes in the coagulation of the blood during the anaphylaxis have led to an interesting and important theoretical conception, namely, that the meeting of antigen and antibody may not, as otherwise believed, lead directly to the formation of a poison, but that in some way the results of such a union may influence the coagulation processes and that these alterations are the direct cause of shock. The first to give serious attention to such a train of reasoning was probably Nolf, and Doerr has recently called attention to the work of a number of investigators (recently confirmed by Moldevan) who observed that freshly defibrinated blood, i. e., blood in which the normal coagulation has been interrupted, may be toxic even when reinjected into the same animal. The same is true of serum taken from rapidly defibrinated blood. There is at least a possibility, then, that the anaphylactic injury is the result of an alteration in the blood indirectly brought about by the union of antigen and antibody. However, the premises for such reasoning are still very vague, and moreover, any view which introduces the various elements which participate in blood coagulating processes can have no part in such manifestations as those observed on isolated and washed tissues, as in the experiments of Schultz and Dale. 
proteins which in the accidents of ordinary life gained entrance. The most clear and thorough exposition of such a point is that which since 1907 has been carefully worked out by Vaughan, and to him belongs the credit for the development of many of the ideas underlying prevalent opinions on anaphylaxis. Vaughan, as you well know, subjected many different proteins, bacterial and others, to hydrolytic cleavage in absolute alcohol containing 2 per cent. of hydroxid.

The protein is covered in flasks with 25 to 30 times its weight of this alkaline alcohol and the mixture boiled at $78 \mathrm{C}$. for an hour or more. In this way he has succeeded in splitting off from a large number of different proteins the toxic fraction.

Since Professor Vaughan ${ }^{10}$ himself has but recently embodied his views in a concise treatise, it is quite unnecessary to go into it more than to review briefly his views. He believes that all true proteins contain a poisonous group which is practically the same in all of them. This poison can become free and active when proteins are submitted to various methods of decomposition. Protein sensitization, in other words, is due to the fact that there is developed after the first injection a specific proteolytic ferment, and this on second injection so acts on the reinjected antigen that the toxin fraction is set free and poisoning results. This, in brief, is Vaughan's point of view and is supported, first, by the fact that such poisons can be formed by his chemical methods from many different kinds of protein; and second, that these poisons, whatever the antigen from which they are derived, may produce symptoms which are in many ways identical with those characteristic of anaphylactic shock. Since, as Vaughan states, proteolysis consists in a gradual breaking up of the protein molecule into simpler and simpler groups, there is an increase of poison liberation up to a certain point in the process; but when it has proceeded beyond this the poison itself is decomposed and ceases to have toxic action. Vaughan believes that anaphylaxis in all its manifestations, whether acute or chronic, is merely an incident in parenteral protein digestion. In the course of this when the relation between circulating antigen and the specific enzyme is such that large amounts of the toxic fraction are suddenly liberated, acute shock follows.

It is hardly necessary to call attention to the attractiveness of such a theory, which so simply explains the apparently mysterious conditions prevailing in anaphylaxis, and there seemed to be very little doubt as to its correctness when Friedemann ${ }^{11}$ some years later showed that the action of fresh unheated serum (i.e. alexin or complement) on sensitized red blood cells will produce a poison that, injected into

10. Vaughan: Protein Split Products, etc., Lea \& Febiger, 1913.

11. Friedemann: Ztschr. f. Immunitätsforsch. u. exper. Therap., 1909, ii. 
rabbits, gives rise to anaphylaxis-like shock. Following him Friedberger $^{12}$ succeeded in producing a similar poison by allowing fresh guinea-pig serum (i.e., complement) to act on both precipitates formed by the union of the serum with its antiserum and on sensitized and unsensitized bacteria. These investigations clearly suggested that the action of the alexin present in the circulating blood, on an antigen sensitized with its specific antibody, might produce protein cleavage in which there was liberated a toxic fraction similar to that produced by Vaughan with his chemical hydrolytic methods. It is but natural, therefore, that Friedberger, to whom the greatest credit in the more recent development of this point of view belongs, should assume that the poison liberated in this way is the toxic factor concerned in anaphylaxis, and name it "anaphylatoxin." For reasons which will appear directly, we think that a preferable term would be "proteotoxins."

The technic developed by Friedberger consists, in the case of dissolved proteins, in allowing the antiserum to act on the serum until a precipitate is formed, then subjecting this precipitate to the action of fresh guinea-pig serum or complement. After a variable number of hours, the length of time depending on secondary factors, which need not be discussed in describing the process, the centrifugation removes the precipitate, the supernatant guinea-pig serum is found to be strongly poisonous, and injected into guinea-pigs intravenously in quantities of from 2 to 4 c.c. produces symptoms typical of acute anaphylaxis. With bacteria his technic is similar. At first bacteria sensitized with inactive immune serum were subjected to the action of fresh guinea-pig complement for from one to two hours at $37 \mathrm{C}$. to as long as twelve to twenty-four hours at refrigerator temperature. At the end of this time the bacteria is removed by rapid centrifugation, and the supernatant fluid injected into guinea-pigs produces again typical symptoms of acute anaphylaxis.

The first interpretation applied to these experiments by Friedberger was an entirely natural one if we consider the general views held before this concerning bacteriolytic and bactericidal processes. $\mathrm{He}$ assumed that the complement acting on the sensitized bacteria or on the sensitized protein in the precipitate experiment (or later on the unsensitized bacteria), produced proteolytic changes in the course of which the toxic split product was formed. It seemed that the poison was pharmacologically the same whatever the antigen used, and experiments also seemed to show that the poison could be produced more rapidly from strongly sensitized than from unsensitized bacteria, and that an excess of sensitization or a too prolonged interaction resulted in nontoxic supernatant fluids, which was taken to indicate that the protein had been split beyond the toxic stage by too energetic hemolytic action.

12. Friedberger: Berl. klin. Wchnschr., 1910, Nos. 32 and 42; Ztschr. f. Immunitätsforsch., 1910, iv. 
Here, then, we have a simple and apparently logical explanation of anaphylaxis, entirely in accord with Vaughan's views of parenteral digestion. An antigen is injected into an animal, specific antibodies and enzymes against it develop in the animal; reinjection of this antigen results in relatively rapid proteolysis in the course of which poisonous substances, the anaphylatoxins, are produced and anaphylaxis is the result. This hypothesis although very attractive does not entirely meet with the facts as they have been developed since Friedberger's first work. The premises on which it is based assume in the first place that the poison or "anaphylatoxin" is formed out of the matrix of the antigen; further, it is definitely assumed that in the production of the poison after the antigen and antibody have met, the complement or alexin plays an active part. Friedberger's hypothesis as stated by him, moreover, seems to assume that the entire process takes place intravascularly, a matter which we will discuss at considerable length in a short time. It is important to note also that Friedberger, with Nathan, was able to show that this anaphylatoxin production could take place within the animal body; that is, within the peritoneum of a guinea-pig into which bacteria had been injected.

The simplicity of Friedberger's explanation and the correctness of his experimental data soon persuaded many investigators that, in essence, his hypothesis probably contained the nucleus of the solution of this difficult problem. However, even his own early experiments aroused some misgivings concerning the matrix of the poisons produced, for he found that the poisons could be obtained as well when boiled antigen was used as when the fresh, unheated substances were employed, and the poisons were easily obtained from such organisms as the tubercle bacillus, which is extremely insoluble and unamenable to serum influence. It was also doubted whether one could truly assume the participation of this specific antibody or sensitizer in the production of Friedberger's poisons, since it soon developed that from bacteria, at least, the poison could be produced when the organisms were directly exposed to the action of fresh guinea-pig serum without the presence of any immune serum.

Experiments which soon threw a definite doubt on the assumption that the poisons were produced by a decomposition of the antigen were reported by Keysser and Wassermann. ${ }^{13}$ These workers substituted insoluble substances like barium sulphate and kaolin for the antigen; that is, the precipitates or bacteria used in Friedberger's experiments. They found that if kaolin were treated with horse serum and then exposed to the action of guinea-pig serum or complement,

13. Keysser and Wassermann: Folia serol., 1911, vii ; Ztschr. f. Hyg. u. Infectionskrankh., 1911, 1xviii. 
poisons were produced identical in every respect to those produced by Friedberger's method. The conclusions they drew were that the poisons were produced, not by action of the complement on the antigen, but by its action on the horse serum absorbed by the kaolin. In other words, they transferred the matrix of the poison from the antigen to constituents in the serum itself, possibly the sensitizer or amboceptor. Bordet $^{14}$ also was able to show that poisons similar to those of Friedberger could be produced by the action of fresh guinea-pig serum on agar, and recently Bordet has further shown that this is the case even when the agar has been by special methods deprived entirely of its nitrogenous components and represents simply a complex of carbohydrates. Agar-guinea-pig serum mixtures of this kind show an increase in total nomprotein nitrogen which would prove that the proteolytic action of the guinea-pig serum must have been active against its own proteins.

An interesting further development of this work has recently appeared in the experiments of Jobling and Peterson. ${ }^{15}$ They showed that when bacteria are mixed with fresh active serum they adsorb the antienzymes normally present in blood. They have shown this experimentally and have proved that similar antienzyme removal can be accomplished by the addition of kaolin or agar, and by treatment with chloroform. Serums so treated become toxic, the actions of the poisons formed showing great similarity to that produced by Friedberger's anaphylatoxins. According to them, the poisons are formed because of the fact that antienzymes are adsorbed by the antigen, thus setting the normal ferments in the fresh serum free to act on their own serum protein.

It should be recalled that Friedemann, who was really the first one to show that the toxic substances could result from the interaction of fresh serum and sensitized antigens, although he succeeded only in doing this with red blood cells, suggested rather early that the success of such an experiment does not necessarily mean that the antigen furnishes the matrix entirely. He had studied the metabolism in anaphylactic poisoning and with Isaac has shown that the nitrogen output following reinjection in a sensitized animal is far in excess of that which could be derived solely from the injected antigen, and in this he has been confirmed by many other workers, notably by Vaughan.

It would seem to us that our present knowledge of this phase of anaphylactic investigation permits us only to conclude that wherever proteolytic changes take place these "proteotoxins" may be formed. That they can be produced from a protein antigen has been shown

14. Bordet: Compt. rend. Soc. de biol., 1913, 1xxiv, 877.

15. Jobling and Peterson: Jour. Exper. Med., 1914, xix, No. 5. 
beyond doubt by Vaughan and his collaborators for both formed and unformed antigens. Also this is evident from the experiments of many workers and has been confirmed in our own experience with poisons appearing during the autolysis of bacterial emulsions. On the other hand, it is also clear that the antigen need not represent the matrix which furnishes the poison, and that in the reactions as they are generally performed both in the test tube and in the animal body, it is more than likely that if an antigen participates at all in furnishing the substratum for the poison, this is probably less important than that furnished by the animal's own proteins. However, this does not weaken the importance of the knowledge that the antigen-antibody reaction in the presence of normal serum and certain antigens in the presence of normal serum alone, induce a reaction in the course of which such poisons are formed. And the fact that they can be produced experimentally in the peritoneal cavity of a living guinea-pig renders their participation in such reactions in the animal body a likely assumption.

Our own work ${ }^{16}$ on these substances induces us to believe that proteotoxins so formed are identical with Bail's aggressins, a point to which we will later refer.

Granted that such a poison, call it "proteotoxin" or "anaphylatoxin" or "serotoxin," as Jobling and Peterson have called it, is formed, it is important of course to determine as closely as possible its nature. Apparently the poison is the same as far as we can determine by pharmacological action when produced by the chemical methods of Vaughan or by the biological methods of Friedberger and others. As obtained by Vaughan it is water-soluble with slightly acid reaction, is freely soluble in alcohol and mineral acids. It is not diffused readily and contains no carbohydrates. In its crude state it gives a biuret reaction, although this may mean simply that the poison has not been completely derived. The fact that the injection of Witte peptone into animals may give rise to symptoms very similar to anaphylaxis has been taken by many workers to signify that the anaphylactic intoxication is produced by a poison which is very similar to, or possibly identical with, the active constituents found in this peptone. After peptone injection in normal animals there is a lowering of blood pressure, a delay in the coagulation of blood and a development of subsequent tolerance, together with many clinical symptoms which emphasize this similarity. Biedl and Kraus, who have especially studied this condition in dogs, have felt emphatically that the anaphylactic poison is probably very similar to peptone. Recently Dale has suggested that $\mathrm{B}$-imidezolylethylamin or histamin may be the active principle con-

16. Zinsser and Dwyer: Jour. Exper. Med., 1914, xx, No. 6. 
cerned in anaphylactic shock. Intravenous injection of $0.5 \mathrm{mg}$. of this substance into large guinea-pigs results in typical respiratory difficulties, convulsions with death and distention of the lungs typical of anaphylactic shock. Treatment with atropin diminishes this action, just as Auer and Lewis found this to be the case in true anaphylaxis, and fall in blood pressure also occurs. It would seem then that substances representing cleavage products of native proteins of highly complex nature, the result of proteolytic cleavage not very far advanced, are probably concerned in the production of anaphylactic shock. The anaphylatoxins of Friedberger cannot of course be studied chemically by the methods to which Vaughan's poisons are amenable.

IV

A further problem which has arisen in connection with the conception of parenteral digestion is that which concerns the participation of complement or alexin in the cleavage process during which the anaphylactic noxious agent is liberated.

When bacteria or red blood cells are sensitized, that is, have been combined with their specific antibodies, we have believed that it is the complement, or active constituents of fresh blood, which then acts on this sensitized complex, either producing hemolysis in the case of sensitized red blood cells, or the bactericidal or bacteriolytic effect in the case of sensitized bacteria. It is also well known to you that this substance, which we call complement or alexin, but about the true nature of which we know nothing, is fixed or bound by dissolved proteins when they have combined, with or without the formation of precipitates by their antibodies. We have ourselves ${ }^{1 i}$ shown that such fixation of complement by precipitates (formed when an antigen and its precipitin have united) is bound in exactly the same way as this occurs in the case of sensitized red blood cells; that it is not a nonspecific physical complement fixation such as that which occurs when complement is fixed by kaolin, yeast cells or other unsensitized emulsion. From this knowledge there has gradually grown the conception that the complement or alexin may be a necessary, active factor in the cleavage of the antigenic molecule. (This may or may not be so; we may say we think that we have no proof at present that the complement acts as a proteolytic enzyme; on the other hand it is more than likely that in some way it is connected with such cleavage processes.) At any rate, since we know that the anaphylactic reaction is the result of the union of an antigen with its antibody, and this together with our knowledge of complement fixation, naturally suggests that the complement may be directly concerned in the mechanism of anaphylaxis.

17. Zinsser: Jour. Exper. Med., 1912, xv, No. 5; 1913, xviii, 219. 
The first method of approaching this problem naturally was the examination of animals with regard to quantitative changes in the complement contents of the blood during anaphylactic shock. It was found by Sleeswijk ${ }^{13}$ that animals actively sensitized and reinjected showed a very definite diminution of complement. However, uncier such conditions the diminution was neither rapid nor very extreme, facts since confirmed by Friedberger and Hartoch, ${ }^{19}$ who found the diminution very much greater in experiments with passive sensitization. In such cases there was a regular and considerable diminution, so that after shock four to eight times as much serum was necessary to produce the alexic effect as before shock. Friedberger even believed that there was a definite parallelism between the intensity of shock and the degree of complement diminution. The question immediately arises is the loss of complement, which we may now regard as a demonstrated fact, an incidental effect of shock or has it causal relationship to the development of shock? The latter seemed at first to be likely for a number of reasons. It was found, in the first place, that the addition of complement to the circulation of an animal during the anaphylactic experiment did not serve to prevent shock. Similar evidence seemed furnished by certain experiments on the complement of birds, by work of Loeffler ${ }^{20}$ and by the observation of Hartoch, ${ }^{21}$ that but slight shock could be produced in guinea-pigs suffering from trypanosomiasis in which, as is well known, complement is greatly reduced. Loeffler also attempted to stupport this point of view by sensitizing guinea-pigs and then reducing their complement by the injection of sensitized beef blood intraperitoneally. Such animals showed diminution of reaction when reinjected with the sensitized antigen. Loeffier's experiments are not conclusive, since the action of the sensitized blood cells in the peritoneum must surely have induced an intoxication not at all unlike that taking place in true anaphylaxis, and, as we have shown recently together with Dr. Dwyer, such intoxications are followed by nonspecific tolerance to the anaphylactic poison.

However, another method of approaching this problem was attempted by Friedberger in his well-known salt experiment. It had been shown by a number of workers, among whom we may mention especially Nolf ${ }^{22.2}$ and Hektoen, ${ }^{23}$ that complement is not bound by sensitized complexes in the presence of hypertonic salt solution. In fact, hypertonicity seems to inactivate complement, and indeed it is a method

18. Sleeswijk: Ztschr. f. Immunitätsforsch., 1909, ii.

19. Friedberger and Hartoch: Ztschr. f. Immunitätsforsch., 1909, iii.

20. Loeffler: Ztschr. f. Immunitätsforsch., 1910, viii.

21. Hartoch and Sirenskij: Ztschr. f. Immunitätsforsch., 1910, vii.

22. Nolf: Ann. de l'Inst. Pasteur, 1900, xiv.

23. Hektoen and Ruediger: Jour. Infect. Dis., 1904, i. 
of many laboratories to preserve complement for considerable periods by adding hypertonic salt solution, in which condition it will last a considerable time and is easily reactivated on dilution to isotonicity with distilled water. Friedberger ${ }^{24}$ injected concentrated salt solution into sensitized guinea-pigs just before reinjection. It is possible, as he found and as we have found since, to inject 0.3 c.c. or even more of saturated salt solution intravenously into guinea-pigs of about 200 grams weight without killing them. When sensitized guinea-pigs were injected in this way and immediately afterwards received a toxic antigen injection, shock was definitely diminished and death averted. This has been one of the strongest bulwarks of those who have believed in the participation of complement in serum anaphylaxis. And it was assumed that the mechanism of the salt experiment consisted in a prevention of complement action. Recently doubt has been thrown on this because Ritz $^{25}$ has shown that salt injection not only prevents anaphylactic shock but will prevent the toxic effects of Witte peptone and of the so-called "anaphylatoxins." Recently with Dr. Dwyer ${ }^{26}$ we have carefully repeated this work and have found that when the dose is carefully adjusted there is no question about the fact that an immediately preceding injection of concentrated salt solution will prevent death or even symptoms in animals injected with proteotoxins. This tends very strongly to diminish the weight of Dr. Friedberger's interpretation of the salt experiment; it means either that the salt in diminishing anaphylactic shock does so by a mechanism not concerned with the prevention of complement, or else it signifies that the so-called proteotoxin itself is not a finished poison as it has been thought to be but must still be acted on by the active constituents of serum before it becomes active.

It is true, indeed, that heating serum to a temperature of $56 \mathrm{C}$. renders it impotent to lead to proteotoxin production when added to antigen in vitro and that this same inactivation destroys the complementary effect on sensitized red cells or bacteria. This, after all, does not prove identity of the substances carrying these activities, but merely establishes an interesting parallelism.

We must not forget that the substance of which we speak as "alexin" or "complement" is not very well understood. We know little of its nature. It has been successfully shown that globulin participation will divide it into two parts, that it will spontaneously reactivate to a slight degree after heat inactivation, that its activity is influenced by concentration, and that it can be inactivated by shaking. We are

24. Friedberger and Hartoch: Ztschr. f. Immunitätsforsch., 1909, iii.

25. Ritz, cited by Doerr: Footnote 29.

26. Zinsser and Dwyer: To be published. 
aware of the fact that we are here, possibly, dealing not with a single substance, but with one of the effects of a complex serum constituent. As to its relation to anaphylaxis we can only say that the diminution of complement during anaphylaxis is perfectly definite. However, we cannot claim with certainty, in spite of the evidence so far advanced, that it plays an active part in the production of anaphylactic shock.

$$
\mathrm{V}
$$

The fact that the hypersusceptible condition can be transferred from a treated to a perfectly normal animal with the blood serum of the former, was in itself one of the first strong arguments in favor of the antigen-antibody conception of anaphylaxis. And this point of view was still more clearly defined when Doerr and Russ ${ }^{27}$ subsequently showed that the power of a serum to convey hypersusceptibility was directly proportionate to its contents of specific antibodies. A serum which was strongly precipitating for the antigen would passively sensitize in quantities far smaller than those necessary for the same purpose in the case of a weakly precipitating serum. The principle that anaphylaxis depended directly on the meeting of the antigen with its specific antibody has never been seriously questioned since this time. However, from the very beginning of experimentation on passive sensitization it has seemed unlikely that the acute reaction, as seen especially in guinea-pigs, could be attributed entirely to the meeting of these two elements in the blood stream. It was observed by Nicolle, Otto, Friedemann, Gay and Southard and by many others since then, that sharp reactions can be produced with regularity only when a distinct interval was allowed to elapse between the administration of the sensitizing serum and the injection of the antigen. When the two are injected together, mixed, or simultaneously, symptoms may be and usually are entirely absent, whereas severe and unfailing shock results when the antigen injection is deferred from twelve to twentyfour hours after that of the sensitizing serum. According to Doerr and Russ the interval may be shortened to four hours, but if lessened beyond this, the reaction may fail to appear, or if present at all is weak and indistinct.

This observation alone would tend to convince us that mere contact within the blood stream of antigen cannot account for the entire train of phenomena and suggests that the characteristic anaphylactic reaction takes place only after the injected antibody has become attached to the body cells in the same manner.

The idea in itself is not new. Wassermann had first suggested it in an attempt to explain the peculiar hypersusceptibility to toxin possessed

27. Doerr and Russ: Ztschr. f. Immunitätsforsch., 1909, iii. 
by some of Behring's toxin-immunized animals. He assumed that in such animals the formation of antitoxins may indeed have been stimulated, but that much of it might still be attached to the generating cells themselves, thereby rendering these proportionately more vulnerable to the injected toxin.

Such a conception of "sessile receptors" was applied by Friedberger ${ }^{28}$ to anaphylaxis in his first attempts to formulate an hypothesis. $\mathrm{He}$ assumed that at the first or sensitizing injection the production of antibodies (precipitins) was stimulated. These, however, were not produced in great quantity and were not discharged into the circulation, possibly owing to the small single dose given for sensitization. They were present at the end of the anaphylactic incubation time as sessile receptors or sessile antibodies (precipitins). On the second injection a reaction occurred between the injection antigen and these sessile precipitins and the cell was injured because the reaction occurred on its substance, a reaction which, it is suggested, might have been harmless had it taken place in the blood stream. In passive sensitization, conversely, no injury could result until considerable quantities of the antibody had become united to body cells in the course of several hours. That the antibody injected into passively sensitized animals indeed disappears from the circulation with relative speed, has been shown by Doerr and again recently by Weil.

Besredka's ${ }^{8}$ early hypothesis, too, though incorrect in most of its premises, assumed the necessity of the intravention of the body cell in anaphylaxis-an opinion here again largely based on the observed interval in passive sensitization; and the same idea occurs at about this time in the work of Doerr and Russ, who likewise conceived the process as taking place directly on the body cell.

It is true as Doerr ${ }^{29}$ has pointed out in a recent summary of anaphylaxis, that these early hypotheses were for a time relegated to the background, yielding the prominent central position to opinions which held that anaphylactic shock was the result of intravascular parenteral digestion. To some degree this is due to the fact that Vaughan's work on the toxic protein split products and Friedemann and Friedberger's experiments on the production of similar poisons by purely biological methods, seemed to offer for the time being a field of work promising logical solution of this difficult problem. At the same time there was much evidence in the published work of such investigators as Friedemann, Scott, Briot, Biedl and Kraus, and Doerr himself which seemed to show clearly that the interval in passive sensitization was not an

28. Friedberger: Ztschr. f. Immunitätsforsch., 1909, ii.

29. Doerr: Ergebnisse der Immunitätsforschung, edited by Weichhardt, Berlin, 1914, i, 257. 
invariable necessity. Consequently and very naturally the early purely cellular conceptions were not accepted as telling the whole story, and a few observers allowed the pendulum to swing completely away from this point of view. Nevertheless it is not fair to say that during this time the cellular theories were entirely neglected. We do not believe that von Pirquet ever entirely abandoned his original opinion that there was involved in certain phases of anaphylaxis an "allergie" of the tissues. Moreover, it was during this period that those methods of research were.first applied to anaphylaxis which furnished in principle and fact all the important premises for the present almost universal cellular point of view. I refer to the transfusion method as employed in anaphylactic dogs by Pearce and Eisenbrey ${ }^{30}$ and the method of observing isolated tissues from anaphylactic animals as used by Schultz ${ }^{31}$ - work which appeared as early as 1910 . Pearce and Eisenbrey working with two normal and one sensitized dog, transfused the blood of one of the normal animals into the sensitized one, transferring the blood of the latter to the normal dog. "At the proper moment the normal dog containing the blood of the sensitized animal and the latter containing the blood of the normal dog, each received intravenously the toxic dose of horse serum." The normal dog having the sensitized blood did not react, the sensitized dog having the normal blood showed typical fall of blood pressure. Pearce and Eisenbrey drew the conclusion "that the phenomenon of anaphylaxis is due to a reaction in the fixed cells and not either primarily or secondarily in the blood."

In the same year Schultz began to work with what is now spoken of as the physiological method. He determined that smooth musclefreshly excised from various animals-will react with contraction when brought into contact with serum. When such muscle was taken from anaphylactic animals after being thoroughly washed free of blood, it would react more energetically and to smaller amounts of the homologous serum. There are many interesting by-products of Schultz's work, such as the differences between fresh arterial blood and blood serum in their abilities to stimulate contraction, but this and other points will not be discussed at present. The important and incontrovertible fact established by Schultz is the changed reaction-energy or, in truth, "allergie" of the smooth muscle of anaphylactic animals to the stimulus of the sensitizing antigen. Dale ${ }^{32}$ has confirmed and extended these observations of Schultz. He removed the uteri from guinea-pigs after thoroughly perfusing them with Ringer's solution to remove all

30. Pearce and Eisenbrey: Congr. Am. Phys. and Surg., 1910, viii.

31. Schultz: Jour. Pharmacol. and Exper. Therap., 1910, i.

32. Dale: Jour. Pharmacol. and Exper. Therap., 1913, iv. 
blood. He then suspended them in baths of Ringer's solution and by the customary physiological methods measured the contractions following the addition of various amounts of foreign protein in the form of -among other things-horse serum and beef serum. He found that the uterus of an animal sensitized to horse serum would react to this substance in dilutions of $1: 2,000$ or $1: 10,000$, while the organ taken from a normal guinea-pig reached its limit of reactionability at dilutions often less than 1:200. A uterus that had reacted strongly was found to be subsequently desensitized. A normal uterus could not-strangely-be passively sensitized by immersion into a solution containing serum antibodies. This method of investigation has recently, also, been taken up by Richard Weil ${ }^{33}$ who has fully confirmed the principles laid down by Schultz and Dale. $\mathrm{He}$ has incidentally also answered an objection to the conclusions of Dale and Schultz (never indeed a very valid objection), namely, that the reaction of the muscle tissue of a sensitized animal might be in part due to the fact that the blood, i.e., the antibodies, had not been entirely washed out of the tissue spaces by perfusion. Weil performed the very simple and ingenious experiment of injecting a normal guinea-pig with large amounts of immune serum (anti-horse serum) and after a few minutes killing the animal. He then suspended the uterus in Ringer's solution in the usual manner without washing it completely free of blood. Contact with the homologous antigen produced no response. We may accept as definitely established by these researches of Schultz, Dale and Weil that the fixed cells of anaphylactic animals possess an increased reaction-ability toward the antigen which is in no sense secondary to processes involving the circulating antibodies. Moreover, the work of Weil seems to indicate that desensitization of a passively prepared guinea-pig deprives the uterus of its power to respond and that the gradual spontaneous diminution of hypersusceptibility on the part of the guinea-pig is accompanied by an entirely parallel loss of reaction-capacity on the part of the isolated uterus.

The recent work of $\mathrm{Coca},{ }^{34}$ too, has further fortified the cellular point of view by a method which in principle is similar to that employed by Pearce and Eisenbrey. Coca succeeded in perfusing actively and passively sensitized guinea-pigs with the defibrinated blood of normal guinea-pigs in such a way that the original blood of the sensitized animals was reduced to a necessarily slight residue. Animals so treated could be kept alive for as long as six hours after the trans-

33. Weil, R.: Jour. Med. Research, 27, 1913; 30, 1914; Proc. Soc. Exper. Biol. and Med., 1914, xi, 86.

34. Coca: Ztschr. f. Immunitätsforsch., 1914, xx. 
fusions and remained delicately hypersusceptible in spite of the blood substitution.

Limiting ourselves for the present to the phenomena of anaphylaxis in which noncellular antigens are employed, we may safely say that the evidence furnished by the incubation time necessary in passive anaphylaxis by the transfusion experiments of Pearce and Eisenbrey and of Coca, and most conclusively by the work on isolated tissue by Schultz, by Dale and by Weil, shows conclusively that the hypersusceptible state is largely determined by a changed reaction-capacity to the specific antigen on the part of the fixed tissue cells-an "alergie" which is probably due to the presence of specific antibodies in the substance of the cell protoplasm, and incidentally accounts for such effects as the skin reactions. It is probable that the acute symptoms and death of anaphylactic guinea-pigs (and indeed of other animals) is in most cases of experimental anaphylaxis due to the reaction which takes place between the injected antigen and these sessile receptors.

So much we must logically accept. However, are we justified in denying all possibility of injury to the animal when antigen and antibody meet in the circulation? This is indeed the claim of a number of workers who are inclined to regard the presence of circulating antibodies not only as incapable of leading to injury, but in fact as a protection, in that the antigen is deflected by them from the antibodies united with the cells. Personally we believe that this radical cellular interpretation of all phases of the phenomena of anaphylaxis goes too far. It was shown by Friedemann as early as 1909 that typical anaphylactic reactions could be produced in rabbits when the antigen (beef serum) was injected simultaneously with or mixed with the serum of passively sensitized rabbits. Indeed Friedemann claimed that by this method severe and fatal reactions could be produced in rabbits more regularly than when an interval was observed. Richet in the same year reported experiments in which immediate symptoms were elicited in dogs injected with mixtures of crepitin and the serum of a crepitintreated $\mathrm{dog}$, the crepitin in quantities far below that necessary to elicit symptoms in itself. (In this experiment of Richet the crepitin and the serum were left in contact in vitro for 20 minutes, a fact which somewhat detracts from the direct bearing of this work on our present discussion.)

In 1910 Biedl and $\mathrm{K}_{\text {raus }}{ }^{35}$ obtained immediate and severe symptoms in guinea-pigs when they injected intravenously mixtures of horse serum together with the serum of sensitized guinea-pigs. Briot ${ }^{36}$ in the same year obtained reactions in young rabbits into which he had

35. Biedl and Kraus: Ztschr. f. Immunitätsforsch., 1910, iv.

36. Briot: Compt. rend. Soc. de biol., 1910, 1xviii, 402. 
injected mixtures of horse serum and anti-horse serum. Gurd ${ }^{37}$ in a recent publication obtained reactions in guinea-pigs when he injected intravenously immune rabbit serum (anti-sheep serum) and immediately thereafter sheep serum. We ourselves have been able to obtain occasional and distinct results in rabbits and guinea-pigs both by simultaneous and immediately consecutive intravenous injections of antigen and antibody, though we did not succeed in attempts to duplicate exactly the experiments of Friedemann and of Biedl and Kraus.

We have here a not inconsiderable mass of evidence which points to the conclusion that the whole story of the anaphylactic phenomena cannot be told by the cellular conception alone, and that probably-as in immunity-both cellular and intravascular processes are involved. Few thoughtful workers on hypersusceptibility would think of denying at present the probably predominating cellular factor in the ordinary anaphylactic type-experiment. I may say that many of us have never doubted that this element was an undeniably important one in serum anaphylaxis since the time when the experiments of Pearce and Eisenbrey and those of Schultz confirmed the suggestion of this conception forced on us by the incubation time in passive sensitization and the studies of von Pirquet. We do not share, however, the exclusively cellular view recently advocated in a recent summary and apparently accepted by Doerr, one of the most capable students of this subject.

It is true that almost all of the workers cited above as having obtained passive sensitization, without the interval, admit the irregularity of such results, and Friedemann, Gurd and others call particular attention to the great importance of the relative amounts of antigen and antibody when these are injected together or in rapid sequence. This has been our own experience and although we have obtained very definite reactions in this way, we feel that in any given experiment success or failure cannot be as regularly foretold as in the experiments in which the interval is allowed. Moreover, the reactions obtained by these methods are often mild-delayed - and are rarely violent or rapidly fatal. We ourselves have never obtained a fatal result. Yet it is idle to say-as has been said-that the reactions so obtained are accidents, probably due to secondary factors, neglible in formulating a conception of anaphylaxis. There is no such thing as an accident in nature, and the observation, though irregular and depending on elements in the experimental procedures not easily amenable to control, has been made too often and independently by a number of different trained observers to be thrown out of consideration in a theoretical scheme which is to be just to all the facts.

37. Gurd: Jour. Med. Research, 1914, xxxi, 205. 
Since we cannot, therefore, deny that under certain circumstances injury to the animal may result from the meeting of the antigen and antibody within the circulation, how are we going to account for the fact that such reactions are difficult to obtain and cannot be obtained with regularity? This question is not a simple one but it is our own opinion that a possible explanation may be found in the failure of rapid union of antigen and antibody in the blood stream. We have already mentioned that all observers who have experimented along these lines have found that very definite proportions between antigen and antibody govern the success of such attempts and that with each lot of serum and anti-serum the optimum proportions must be determined by experiment. In Friedemann's work on rabbits he found that the relative amounts of antigen and antibody which produce reactions in his rabbits if injected together corresponded roughly to the proportions which in vitro gave precipitates. An excess of one or the other substance would prevent reaction or at least result in a negative experiment. Now it is well known to all who have worked with antiprotein serums that the precipitin reaction can be inhibited by an excess of one or the other reagent.

When a constant amount of precipitating serum is used, the most prompt and voluminous precipitation may, for instance, occur when the antigen dilution is $1: 50$, and both the speed and the amount of precipitate may diminish not only as this dilution is increased, but also as the concentration is increased. This is a phenomenon which is common to all colloidal reactions and the mutual precipitation of the two colloids is to a large extent dependent on relative proportions.

It is a well-known fact (also familiar to many of you) that Linossier and Lemoine, ${ }^{38}$ Eisenberg, ${ }^{39}$ Ascoli, ${ }^{40}$ von Dungern ${ }^{41}$ and others have frequently noticed that animals treated with a foreign protein such as horse serum, for instance, may contain in their blood serum, as late as six, seven, eight or more days after injection, both the antigen and its antibody ununited and separated. Thus we have often seen ourselves, if we bleed an animal that has been rapidly treated with such a foreign protein, that its serum will precipitate horse serum, and will at the same time be precipitated by anti-horse serum taken from another rabbit. It is thus plain that the serum in the case mentioned contains not only horse serum as such (a remnant of that injected) but also antibodies against horse serum which have been formed in response to the injection. It is unquestionable from the experiments of others and from our own extensive confirmation, that

38. Linossier and Lemoine: Compt. rend. Soc. de biol., 1902, liv, 85.

39. Eisenberg, P.: Centralbl. f. Bakteriol., 1903, Orig., xxxiv, Part 1, p. 259.

40. Ascoli, M.: München. med. Wchnschr., 1902, xlix, 1409.

41. V. Dungern: Centralbl. f. Bakteriol., 1903, Orig., xxxiv, Part 1, p. 355. 
the serum of such an animal may contain side by side free antigen and free antibody. Why have these failed to unite? If such a serum is allowed to stand at room temperature or in the ice box there will take place a very slow precipitation and a concomitant diminution in the amount of precipitin present. The precipitate thus formed has slight and distinct complement-fixing properties. Slow union, therefore, is taking place.

Another strange fact about such serums is that if two such rabbits are prepared, in each of which both free antigen and antibody can be determined, these serums when mixed will promptly precipitate each other.

A number of explanations have been advanced for the simultaneous presence of antigen and antibody in the same serum without union. Eisenberg and Volk have attempted to explain it by dissociation-that is the antigen and antibody are present united and also dissociated, reacting according to the laws of mass action. This has seemed to us unlikely. For, were this the case, the serum, as taken, should in itself exert definite complement-binding properties, since on the basis of this explanation it must contain not only the two reagents separate but a rather large proportion of the antigen-antibody complex united. This is not the case according to our own observations and according to similar ones made by Gay and Rusk.

Von Dungern ${ }^{42}$ has assumed that the state of affairs described was due to the fact that the antigen might contain a number of different substances, alpha, beta, etc., each of which produces its own specific Teil-präzipitin. He believes it possible that at certain stages in the immunization the free antigen present might be, say, an alpha fraction, the free antibody, let us say, a beta precipitin, the two not fitting and therefore unable to react.

Auch hier handelt es sich nicht um zwei reaktionsfähige Körper, deren Verbindung aus irgend Grunden unterbleibt, sondern um Substanzen, welche keiner Affinität zueinander besitzen. Die betreffenden Kaninchen haben zu dieser Zeit noch nicht alle möglichen Teilpräzipitine gebildet, sondern nur einzelner derselben. Diese zunächst produzierten, nur auf bestimmte Gruppen der präzipitablen Eiweisskörper passenden Partialpräzipitine sind es, welche nach der Absättigung aller zur Verfügung stehenden zugehörigen Gruppen der präzipitablen Substanz im serum nachweissbar werden. Daneben bleit aber ein anderer Teil der präzipitablen Substanz, der keiner Affinität zu dem gebildeten Präzipitin besitzt, bestehen, solange bis ein anderes Partialpräzipitine von den Kaninchenzellen geliefert wird welches sich mit Gruppen der in Lösung gebliebenen Eiweisskörper vereinigen kann.

This has not seemed likely to us although they are clear when taken and remain so for considerable periods, but do eventually precipitate

42. Von Dungern: Centralbl. f. Bacteriol., 1903, xxxiv, first part orig. 
slowly and in the course of days, an observation made not only by us but by Merckel.

It has seemed to us most likely that there might be in the circulation of animals an inhibiting agent, somewhat in the nature of a protective colloid, which prevented the union of antigen and antibody, or at least tended to make it an extremely slow process.

We may assume in the light of our present knowledge that both the antigen and the antibody are colloidal in nature, and together with Stuart W. Young, ${ }^{43}$ we have been able to produce an analogy to the condition found in the serums just described by using three colloidal suspensions, that is, arsenic trisulphid, gelatin and gum arabic. Emulsions of gelatin flocculate suspensions of arsenic trisulphid; if small amounts of gum arabic are added flocculation is prevented. In order that a protected suspension shall be produced in which no precipitation will occur, very definite proportions between the three suspensions must be arrived at, but a number of quantitatively varying mixtures of the three can be produced which will hold up without precipitating for a considerable period. Like the serums described above, two such suspensions in which the relative proportions of the three are not the same will precipitate each other when by rapid mixing the quantitative relationship necessary for protection is suddenly disturbed.

We have here, then, a complex analogy to the conditions in the serums. Two substances, mutually flocculable, do not precipitate. They are prevented from precipitating by the presence of a third substance which "protects" when certain definite proportions between the three are maintained. Many quantitatively different mixtures of this kind may be made in which flocculation is in this way prevented. Mix two such protected mixtures, disturb these proportions and flocculation occurs, faster or slower according to the relations arrived at in the mixtures.

Moreover Porges ${ }^{44}$ has shown that the factor of colloidal protection may well play a part in the occurrences taking place in a medium of blood plasma or serum. He has found that fresh native serum will precipitate mastic emulsions. The same serum heated, if used in very small quantities, will protect mastic emulsions against precipitation of the fresh serum. This alone shows what delicate physical changes in the body fluids may make for fundamental changes of reactions.

In our own experience these experiments of Porges were in principle confirmed; small quantities of heated dog serum added to arsenic

43. Zinsser and Young: On the Possible Importance of Colloidal Protection in Certain Phases of the Precipitin Reaction, Jour. Exper. Med., 1913, xvii, 396.

44. Porges, O.: In Kraus and Levaditi: Handb. d. Technik u. Methodik der Imm., Jena, 1909, ii, 1146. 
trisulphid precipitated this suspension; slightly greater quantities again dispersed it. Of similar significance are experiments by Streng on the so-called conglutinins, substances in serum which are supposed to produce an agglutination of blood corpuscles or bacteria which have been previously treated with fresh serum or alexin. The addition of minute quantities of alexin to typhoid bacilli and agglutinin prevents agglutination.

Friedemann, ${ }^{45}$ furthermore, a pioneer in this branch of serum investigation, in studies on the serum reactions has come to the conclusion that certain anticomplementary activities of the serum globulins may be inhibited by the albumins of the same serum. Schmidt ${ }^{46}$ speaks of a similar Schutzwirkung on the albumin of normal serum. When lues serum was mixed with certain lipoid extracts (of human heart, used for Wassermann antigen) precipitation resulted. Such precipitation was brought about also by the globulins of normal serum-but was prevented or "protected against" when the albumin of normal serum was added to the mixtures. Friedemann himself (and Schmidt agrees with him on the main points) thinks that the globulins and albumins of normal serum are in antagonism, the albumins preventing certain reactions (such as complement fixation) in which the former become active as soon as the albumins are removed or diminished.

We do not have to force analogy to look on such serum reactions as essentially following laws similar to those observed in the case of chemically definable colloids. Apart from the protein character of serum constituents, we know that serum reactions follow quantitative laws analogous to those observed in colloidal reactions (inhibition zones, etc.). We know the importance of the electrolytes in the phenomena, we know that the immune bodies like the colloids diffuse but slowly, and we know from the work of Landsteiner and Pauliti especially, that certain serum hemagglutinins will wander, like other colloidal substances, to one pole or the other when a direct electric current is passing through solutions containing them, like amphoteric substances changing the direction of wandering according to the alkalinity or acidity of the menstruum. The points of similarity are too numerous to be exhaustively reviewed in this connection. They are so many and so striking, however, that we should hesitate to apply any explanation to serum phenomena of any kind which is not in accord with the general behavior of colloids.

In recent experiments of our own, moreover, we have been able to show that when precipitin reactions are set up in comparative series,

45. Friedemann: Ztschr, f. Hyg., 1910, Ixvii.

46. Schmidt: Ztschr. f. Hyg., 1911, 1xix.

47. Landsteiner and Pauli: Cited from Landsteiner, "Colloide u. Lippoide in der Immunität," from Kolle and Wassermann, Ed. 2, ii, 1244. 
in one case using the globulins of normal rabbit serum, in salt solution, as the diluent for the antigen, and in another series the albumins of the same serum, the reactions in the latter are noticeably slower than in the former-than similar reactions in salt solution or in active or inactive serum. There is apparent inhibition of the reaction by the serum-albumin.

Enough has been said to show the justification of any theory which utilizes as a major premise the possibility of the participation of protective colloids in reactions taking place within the vessels of an animal. We suggested some years ago in a paper on this subject that it was such a protective colloidal action in the plasma of animals which prevented the rapid union of antigen and antibody in the blood stream, and we thought at the time that such an arrangement would indeed constitute an automatic protection of animals against sudden and severe injury when a foreign protein gained entrance to the blood stream. Our conception of the whole process would therefore be something as follows: The injection of a foreign antigen into the animal body leads it to antibody formation by the tissue cells. These antibodies are in part discharged in the blood stream and in part sessile on the cells. There is a gradual union between the circulating antigen and antibody and probably between the circulating antigen and the sessile antibodies. Under conditions apt to occur in the course of normal conditions the quantity of antigen which gains entrance is small and no injury results from such union by which probably a gradual parenteral digestion of the foreign substances is obtained. When in the course of abnormal states, infectious disease, etc., a situation arises in which considerable amounts of antibody have been formed and relatively large amounts of antigen are also present, all the conditions are furnished for what we call anaphylactic injury, unless there were some efforts to prevent the rapid union in these antibodies. In the anaphylactic experiment we see that the rapid union of antigen and antibody on the cell will kill. But it is likely that in most cases during immunization the circulating antibodies are far in excess of those still sessile on the cells, and were rapid union between these and the antigen not inhibited in the circulation, the animal would be constantly and severely ill during all processes of immunization. However, we know that in highly immunized animals antigen and antibody may be present side by side ununited. Is it not necessary to assume that this is evidence of a protective inhibition of union? For the colloidal protection would lead to a very slow union, in which, because of the gradual nature of the process, practically no severe injury of the individual could result. According to this conception we can quite easily explain why the simultaneous injection of antigen and antibody into the normal animal 
would result ordinarily in slight and delayed symptoms. Accidental success in so balancing the proportions that complete elimination of protection results would account for the occasional acute symptoms and death observed in such procedures. It is quite clear that such an ideal experiment cannot be regularly obtained, for the simple reason that the protective element may be subject to variation, and since there are so many secondary factors even in test tube experiments on precipitation which influence such reactions.

When the animal is sensitized by the methods of the classical anaphylactic experiment, the union in the cells, violent and stormy, results in death after anaphylactic shock, and whatever symptoms might have resulted from the union of the two substances in the blood serum are overshadowed and secondary.

It is perfectly clear that there are many gaps in the absolute experimental proof of such a conception. We know, however, that slow, gradual and acute injury may follow on the simultaneous interaction of antigen and antibody in the animal body. We know from the many experiments of Vaughan, Friedberger and of others that in vitro such a meeting in the presence of active serum can result in the production of injurious substances which produce anaphylaxis-like symptoms when injected into the animal. We know from the experiments of Doerr that the injection of formed precipitates will injure. Whatever we may think about the nature of the poison and its mechanism of production there is little reason to doubt that the noxious agent can be produced without reference to the body cells. And we believe from this, together with the premises on which we have developed our idea of colloidal protection, that such a conception may form a perfectly legitimate explanation for the scattered and yet definite observations made since Friedemann, by many others and by ourselves, of immediate symptoms after simultaneous injection of antigen and antibody.

VI

In discussing the probable localization of anaphylactic reactions in the preceding paragraphs, we limited ourselves entirely to the phenomena occurring when sensitization is carried out with noncellular substances such as blood serum, egg albumin, etc.

When the antigen employed is cellular, consisting of bacteria or red blood cells, we are confronted with a problem of considerably greater complexity. As morphologically compact structures these cells cannot enter into direct chemical relations with the fixed tissue cells until they have been either disintegrated or at least have given up constituents to solution in the blood plasma. In consequence we must assume two separate phases of all such reactions--one the occurrences within the 
circulating blood in which the injected cells come in contact with the solvent elements of the plasma and during which the solution of antigenic constituents is brought about, the other the subsequent reactions entered into by these dissolved substances, either within the circulation or on the fixed tissue cells with their respective receptors or antibodies.

If therefore Doerr ${ }^{29}$ and others (Denzer and Weil) claim that anaphylaxis with cellular antigens is entirely similar in principle to that produced with dissolved, unformed antigens, they may well be perfectly right in so far as the second phase of these phenomena is concerned. They found that guinea-pigs injected with hemolytic serums reacted to the injection of the blood cells when, as in passive serum anaphylaxis, a latent period or interval was allowed to elapse between the administration of the antibodies and that of the nitrogen. This means simply that they failed to obtain acute or marked symptoms (for quantitative reasons possibly) when the cells and antibodies met in the blood stream.

Analyzing the phenomena in this way it becomes clear that when we inject cellular material we are merely injecting an antigen-or more probably a group of antigens-enclosed in the morphological structures of the cell, and amenable to reaction only after liberation. After this has taken place, subsequent occurrences should in no important principle differ from those following on the injection of an unformed substance like serum, or we may say for the sake of clearness, a predissolved antigen; and all that we have said about such conditions in our preceding discussion should apply here.

Added to this, however, we have in the case of cellular antigens a process unnecessary when unformed antigens are injected, namely, the cytolytic or cytotoxic reaction which precedes the liberation of the cell-constituents, and in the course of which the formed elements are broken up. And we need only compare the slow autolytic disintegration of cells in sterile inactive serum or salt solution with the rapid changes occurring in active hemolytic or, in certain cases, in bacteriolytic serums, to be convinced that such disintegration is due to reaction with active serum constituents.

We may logically accept, then, that by injecting cells, we are for one thing injecting substances which will, in part, soon be liberated and which will call forth all the changes and enter into all the reactions which are associated with the injection of dissolved antigens. In addition to this, however, we are confronted with a further problem. Is there injury to the animal body, comparable in broad principles with anaphylaxis, during this intravascular reaction between whole cell and 
cytolytic antibodies which precedes the liberation of the soluble constituents? Is there, in other words, a true "cell anaphylaxis"?

Since it is probable that the principles of cellular anaphylaxis are the same whatever the variety of cell employed, we may take red cell hypersusceptibility as a basis for discussion. It is a well-known fact, long recognized, that a serum which is capable of hemolyzing the red cells of any species is toxic when injected into an animal of this species. This is true not only of hemolytic serums but also of such normal serums which like, let us say, goat serum and rabbit cells, can hemolyze normally the red cells of another animal. Since occasionally the serum of an individual of one species can so act on the red cells of another individual of the same species, our surgeons call for careful investigation of receptor and donor before performing transfusion. The injection of such a serum intravenously may kill with symptoms not unlike anaphylactic shock. Here it is often difficult, as we shall see (or indeed it may be impossible), to determine, whether such death is truly anaphylactic in nature or whether it is due to clumping of red cells or hemagglutination, a property which is very often an accompaniment of hemolytic power. However, hemagglutinating properties cannot be held responsible for the edema and localized injury which, as Uhlenhuth and Haendel have shown, may follow the subcutaneous injection of such serums. It thus appears as though the process of hemolysis were accompanied by the liberation of injurious products.

The first systematic investigation of red cell anaphylaxis was undertaken by Ulrich Friedemann. ${ }^{11}$ Friedemann injected washed beef cells into rabbits and followed this by a second injection after from seven days to three weeks. Rabbits so treated showed the symptoms ordinarily associated with anaphylaxis in these animals. Active sensitization seems thus to have been accomplished with beef cells. Schiff and Moore have recently suggested that Friedemann really obtained serum anaphylaxis, but since Friedemann explicitly states that he worked with washed cells, we can see no just reason for such an assumption. Another objection to Friedemann's results, however, is possible-one which is far less easy to controvert-namely, that the illness of his rabbits may have been due to hemagglutination, which by itself may produce serious illness or even death by mechanical obstruction of blood vessels. Friedemann, indeed, takes cognizance of this possibility but makes no attempts to rule it out in his experiments. As a matter of fact we think it unlikely that hemagglutination played a part in his rabbits, but the possibility cannot be excluded. We will revert to this particular question.

Passive sensitization was produced by Friedemann against beef cells in rabbits by injecting the specific hemolytic serum. He obtained 
his best results when he injected serum and cells together, mixed in vitro. However, he also obtained positive experiments when the two were simultaneously injected into opposite veins. His results were inconstant when he allowed an interval to elapse between serum and cell injection - a fact which argued for the direct occurrence of the reaction within the circulation.

Most important of all, Friedemann mixed hemolytic serum and cells in test tubes, letting them stand for five minutes in a water bath and then, before any considerable degree of hemolysis had taken place, he centrifugalized and injected the faintly red supernatant fluid into rabbits. A rabbit so injected became extremely ill and many of them died after shorter or longer intervals, with symptoms typical of anaphylaxis in rabbits. Friedemann concluded that when red cells came in contact with hemolytic antiserum, poisonous substances were liberated, even before actual hemolysis had taken place, and that these toxic products were responsible for the subsequent injury to the animal. $\mathrm{He}$ identified the anaphylactic antibody with the hemolysin. This view, therefore, is identical in principle with the one we have discussed as the conception of parenteral digestion. Indeed Friedemann's experiments furnished the point of departure for Friedberger's subsequent work on the so-called "anaphylatoxins."

Doerr and Moldovan, ${ }^{48}$ a little later (1910), studied the effects of the injection of serums hemolytic for guinea-pig erythrocytes into guinea-pigs, and drew conclusions which substantiated those of Friedemann. They found that the toxic effect was due to the action of the hemolytic serums on the guinea-pig erythrocytes. Toxicity could be removed from such serums by absorption with these cells, and the toxic products could be produced by contact of serum and cells in vitro. From these experiments, again, it seemed that the liberation of a toxic substance followed on contact between erythrocytes and specific antibodies, whether this contact took place within the circulation or in the test tube. That the antibodies concerned need not necessarily be identical with hemolysins themselves follows, we think, from the work of Doerr and Moldovan as well as from work of our own on the toxicity of certain normal serums ${ }^{49}$ - experiments which could not be discussed in detail without taking more space than seems justified.

Although much irregularity of result has been obtained in the production of active erythrocyte anaphylaxis in both guinea-pig and rabbit experiments, nevertheless, it seems clearly established that acute death does follow the repeated injection of such cells when dosage and interval are properly observed. The recent experiments of Schiff and

48. Doerr and Moldovan: Ztschr. f. Immunitätsforsch., 1910, vii.

49. Zinsser: Jour. Exper. Med., 1911, xiv, No. 1. 
Moore, ${ }^{50}$ though they clearly illustrate the difficulties of such procedure in guinea-pigs, still record a sufficient number of positive results to reconfirm its actual occurrence. From one of these experiments, indeed, as well as from the experience of Friedemann and others with passive sensitization by antierythrocyte serums, it would appear that with red cells the phenomenon requires a procedure differing from that successful with serum anaphylaxis, in that a considerable concentration of antibodies is needed, i.e., a condition calling in the active experiment for more than one preparatory injection, or, in the passive sensitization, for the injection of a serum of high potency. This, as we know, is the case, also, in bacterial anaphylaxis, in which experiments are usually successful only if many and repeated preparatory injections are made. It is this factor, possibly, which may account for the failure of so many workers to obtain true cell anaphylaxis when they have followed the technic successful in the serum experiments-i.e., that of only one preliminary sensitizing dose-or that, in the passive experiment, many have failed to duplicate Friedemann's success when both antigen and sensitizer were simultaneously injected. It is more than likely that a weak sensitization and consequently a slow reaction between the cells and the antiserum may be interrupted by prompt phagocytosis of the injected cells, with consequent protection against the further developments of the process.

It is true that in many cases of erythrocyte anaphylaxis it may be impossible to say with certainty whether death was due to true shock or whether it was caused by embolic processes due to hemagglutination. This possibility has not been ruled out in many otherwise complete investigations-though in experiments like those of Friedemann and Amako $^{51}$ it seems but a remote possibility. However, in individual instances, such as our own experiments with normally toxic serum, it has been shown that the toxicity may disappear with inactivation, though hemagglutinating properties are retained, and it seems that, to kill acutely hemagglutination must be rapid, powerful and extensive. Moreover, the speed and completeness of recovery showing non-lethal degrees of erythrocyte anaphylaxis argues at least against the frequent occurrence of hemagglutinative death by embolism in experiments carried out in this way. The local injury following the subcutaneous injections of normal and immune hemolytic serums must of course occur entirely independent of hemagglutination. Finally, the fact that contact of the cells with active serum-as first carried out by Friedemann-produces a poison in vitro which kills acutely with symptoms of anaphylaxis, seems to render fairly certain the assumption that

50. Schiff and Moore: Ztschr. f. Immunitätsforsch., 1914, xxii.

51. Amako: Ztschr. f. Immunitätsforsch., 1914, xxii. 
similar contact in the circulation may lead to like result. For we know that the entire process of hemolysis can take place intravascularly.

Whether the antibodies that so react with the cells are the hemolysins themselves, is a question that we hardly have the time to discuss and which moreover is merely an incidental one. After all, hemolysis itself is merely one visible result of a reaction which probably affects profoundly the entire cell structure. About bacterial anaphylaxis our knowledge is still more defective than is that occurring when erythrocytes are used. We do know, however, that active sensitization with bacterial proteins and with whole bacteria is possible-though many injections are apparently necessary - the exact procedure being subject to so many fortuitous influences that so far no regularly successful method can be outlined. We also know that, as with red cells, contact between the bacteria and active serums will result in the production of acutely toxic substances-which we have discussed above as "proteotoxins."

\section{SUM MARY}

We may summarize our views on cell anaphylaxis, briefly, as follows: When whole cells are injected into an animal two distinct processes are set in motion. First, the formed cells come into relation with circulating antibodies. During this contact toxic substances"proteotoxins"-may be set free if quantitative relations are suitable and cells sufficiently sensitized. Where the matrix of the poison is found and to what an extent the complement participates-these are in many respects still open questions. This reaction alone, if sufficiently vigorous, may cause acute symptoms and even death.

During this reaction antigenic cell constituents are set free to solution and these then enter into reaction with their respective antibodies or receptors in the blood or on the fixed cells. The last-named reactions are entirely comparable to those of serum anaphylaxis and have been sufficiently discussed.

Whether in the first-named process, when the whole cell meets its antibody in the blood stream, we regard the poison as originating from the matrix of the antigen or from the serum itself by the withdrawal of antienzymes is immaterial. The reaction is subject to so many modifying factors that experimental control is made difficult and results cannot at present be so regularly foretold as is the case in serum anaphylaxis. It seems probable from the work of Friedberger and others that a delicately balanced optimum proportion between antigenic cells and antibodies must be obtained. Moreover, unless the process is rapid and harmful effects very sudden, prompt phagocytosis of the cellular elements may remove the antigen from further reaction possibility. 
It is plain that such a conception has the greatest importance in the understanding of infectious diseases. When bacteria form the antigen which gains entrance to the animal body, the gradual stimulation of specific antibodies in the animal may eventually lead to such a two-phase reaction. Specific sensitizers or amboceptors (cytotoxins) are gradually formed and these may react with the dead and the living micro-organisms. There may be a direct formation of proteotoxins and at the same time a liberation of soluble antigen from the bacteria. It may be, as von Pirquet has suggested, that the sufficient establishment of such reactions between cell and antibody may mark the end of what we speak of as "incubation time," no noticeable time accruing to the animal body until the antigen-antibody reaction has been initiated. The "proteotoxins" so formed, whatever their matrix, may then, as we have shown with Dr. Dwyer, act as aggressins, lead to a leukopenia, as in typhoid fever, and thereby increase indirectly the invasive capacity of the micro-organisms. The antigenic substances which have gone into solution may at the same time react both on the fixed cells with sessile receptors, and, to a merely incidental degree, with their receptive circulating antibodies, adding thereby to the injury sustained by the host.

True immunity against dissolved antigens, we have stated in the beginning, probably does not exist, for animals having high antibody contents in their serum may still die suddenly with convulsions after a fourth or fifth injection with foreign serum. In the case of cellular antigens, however, and especially bacteria, true immunity may exist in two forms. On the one hand if the animal possesses a high concentration of antibodies before the micro-organisms have gained entrance, an immediate bactericidal effect may prevent their multiplication, the harmful effects resulting from the union of the small initial amounts of antigen and antibody being so slight as to be unnoticeable. Again, after the bacteria have gained entrance, if the quantitative relations between antigen and antibody are such that the reaction is either slight or for purely quantitative reasons results in little injury for the time being, then sensitization of the bacteria or other cells by the antibodies, leads to rapid phagocytosis. And this process of phagocytosis represents true immunity, a removal of bacteria incidental to which there is, as far as we know, no injury to the host. It is in the process of phagocytic removal, chiefly, in which the reaction to cell injection differs from that taking place in response to the administration of unformed protein. It may be this element which renders it so difficult to obtain sharp anaphylactic reactions with cellular antigens. And it is the absence of phagocytosis in the latter case which probably prevents the existence of a true immunity. 